\title{
CONCEPÇÕES DE SAÚDE NA PAUTA SINDICAL DA CONFEDERAÇÃO NACIONAL DOS TRABALHADORES EM EDUCAÇÃO
}

\author{
CONCEPTS OF HEALTH ON THE AGENDA OF THE NATIONAL \\ CONFEDERATION OF EDUCATION WORKERS
}

\author{
CONCEPTOS DE SALUD EN LA PAUTA SINDICAL DE LA CONFEDERACIÓN \\ NACIONAL DE LOS TRABAJADORES EN EDUCACIÓN
}

Leda Aparecida Vanelli Nabuco de Gouvêa ${ }^{1}$

Resumo O objetivo deste trabalho é identificar e analisar concepções de saúde presentes nas reivindicações dos professores, na Confederação Nacional dos Trabalhadores em Educação. Trata-se de resultado de pesquisa documental realizada nas resoluções congressuais da entidade sindical, abrangendo os anos de 1999 a 2014. Por meio de análise de conteúdo, as referências à saúde presentes nos documentos foram classificadas em reivindicações próximas a uma natureza econômico-corporativa ou éticopolítica. Os resultados da pesquisa indicam que, além de uma concepção restrita, marcada por reivindicações corporativas, há uma concepção ampliada presente na documentação investigada. A reivindicação da saúde, sob a perspectiva de um direito social, garantido mediante políticas públicas, pode ser um caminho fértil para a defesa da saúde no seu sentido ontológico, e não como um fator econômico, compreendido como mercadoria e suficiente para a reprodução da força de trabalho.

Palavras-chave docentes; saúde do trabalhador; direito à saúde; sindicatos.
Abstract This article aims to identify and analyze the concepts of health present in teachers' demands at the National Confederation of Education Workers, in Brazil. It is the result of a documental research carried out on the resolutions of congresses held by the labor union in the period from 1999 to 2014. Using content analysis of documents, references to health were classified in demands either of economic-corporative or ethical-political nature. The results of the documental investigation indicate that, besides a strict concept of health marked by corporative demands, there is also a broad concept of health. The demand for health under the perspective of a social right guaranteed through public policies may be a fertile pathway for the defense of health in its ontological sense, rather than as an economic factor understood as merchandise and sufficient to reproduce the workforce.

Keywords teachers; occupational health; right to health; labor unions. 


\section{Introdução}

A problemática discutida neste artigo emergiu de três situações: a primeira é que, desde o final da década de 1990, que as pesquisas nacionais, nos âmbitos acadêmico e sindical, identificaram o perfil do adoecimento dos professores e denunciaram o seu afastamento do trabalho devido a doenças profissionais (Gasparini et al., 2005; Leite e Souza, 2011; Apeoesp, 2012; Caldas, 2012; Robalino, 2012.); a segunda diz respeito às análises realizadas por pesquisadores na área da saúde do trabalhador, as quais fazem menção ao sindicalismo brasileiro que não vem defendendo a saúde como direito (Lacaz, 1997; Dias e Hoefel, 2005; Lacaz e Santos, 2010); e a terceira é a pesquisa realizada na base de dados da Biblioteca Virtual da Saúde, que propiciou identificar uma lacuna na produção científica brasileira, no tocante à temática saúde e sindicalismo. Neste contexto, o objetivo deste trabalho é identificar e analisar que concepções de saúde estão presentes nas reivindicações dos professores, em uma entidade sindical. Trata-se de estudo que fez parte de tese de doutorado, defendida no ano de 2015 e não apresenta conflito de interesses.

A Confederação Nacional dos Trabalhadores em Educação (CNTE) foi a entidade sindical estudada. Inaugurada em 1990, ela representa os trabalhadores da educação de escolas públicas, como os professores dos ensinos fundamental e médio, funcionários, especialistas da educação e diretores (Vieira, 2010). Em 2015, um total de 50 sindicatos estava filiado à CNTE; desta forma, mais de 2 milhões de professores e professoras da rede básica e pública, alocados em diferentes regiões do país, são representados pela instituição (CNTE, 2016).

\section{Delineamento do estudo}

Para atingir o objetivo proposto, foi realizada pesquisa documental nas resoluções derivadas dos seguintes congressos nacionais da CNTE: $27^{\circ}$ (1999), $28^{\circ}(2002), 29^{\circ}(2005), 30^{\circ}(2008), 31^{\circ}(2011)$ e $32^{\circ}(2014)$. A coleta e o tratamento dos dados obtidos seguiram a técnica da análise de conteúdo que, conforme Gomes (2001), apresenta duas funções básicas: verificar hipóteses ou respostas para questões formuladas e descobrir conteúdos que não se manifestam na comunicação. Neste sentido, definiram-se temas de saúde como as unidades de registro para a análise do conteúdo dos documentos. Preliminarmente, procedeu-se a uma descrição de cada uma das resoluções congressuais e demarcaram-se algumas das proposições de luta em relação aos temas de ordem trabalhista e das políticas educacionais, com o intuito de contextualizar as referências à saúde registradas nos documentos. Cada excerto (referência à saúde nos documentos), no final do processo de descrição, foi classificado por unidade temática. O projeto de pesquisa foi aprovado 
pelo Comitê de Ética e Pesquisa da Universidade do Estado do Rio de Janeiro, mediante o parecer número 902.548, datado de 03/12/2014.

\section{O aspecto econômico-corporativo e o ético-político na agenda da saúde da CNTE}

A problematização da saúde/adoecimento dos professores foi iniciada pela CNTE no final da década de 1990. O período indicado foi um momento histórico, vivenciado pelos professores nas redes públicas de ensino, marcado pelo movimento de expansão e universalização da educação básica. Tais eventos, além de aumentarem o número de professores nas escolas públicas, também promoveram a emergência de novas formas de gestão do trabalho, novos currículos, conteúdos e tecnologias educacionais. Tudo isso, no contexto de ampliação do acesso de crianças, adolescentes e adultos à escola. Diante de novas demandas para a escola e para os professores, o trabalho docente passa por um processo de precarização (Oliveira, 2012), que prejudica tanto a qualidade de ensino como a saúde dos professores. Para a CNTE, além da ampliação e modernização de sua agenda política, de acordo com os novos tempos, foi uma ocasião de parcerias, com vistas à realização de estudos, a fim de se conhecer melhor o professorado brasileiro e suas condições de trabalho.

Publicações como Educação: carinho e trabalho - Burnout, a sindrome da desistência do educador, que pode levar à falência da educação, organizada por Wanderley Codo, em 1999, resultante de pesquisa nacional realizada pelo Laboratório de Psicologia da Universidade de Brasília, em parceria com a CNTE (Codo, 2002), e "Retrato da escola 3: a realidade sem retoques da educação no Brasil - Relatório de pesquisa sobre a situação dos trabalhadores(as) da educação básica" (CNTE, 2003), marcaram a problematização da questão na sua dimensão coletiva, ou seja, como um problema da categoria profissional (Gouvêa, 2016).

Dos dois estudos citados, conforme Gouvêa (2016), é possível depreender que foi com o tema da saúde mental dos trabalhadores da educação que se iniciaram os debates na instituição e, em 2003, por meio de nova pesquisa da instituição, procurou-se avançar no sentido de se apreender a relação entre condições de trabalho e saúde dos professores. Os principais problemas identificados nas pesquisas citadas podem ser resumidos nos seguintes aspectos: aumento do número de afastamentos do professor para tratamento médico, trabalho do professor exercido mediante adoecimento, sobrecarga de trabalho, infraestrutura escolar precária e violência na escola.

Diante dessas constatações, a CNTE assimilou em sua agenda política a questão saúde/adoecimento docente. Pela pesquisa documental, nas resoluções congressuais da entidade sindical, de 1999 a 2014, foi possível identifi- 
car que concepção de saúde esteve presente nos debates e na agenda política aprovada naquele período.

Para se apreender a concepção de saúde presente nos documentos elencados, buscou-se o sentido das reivindicações por saúde presentes nos referidos documentos institucionais, e empregou-se o referencial teórico e metodológico de Gramsci (1986, 1984), mais precisamente, sua análise de situações.

Em uma apresentação bastante sucinta da referida elaboração teórica de Gramsci, no primeiro momento da análise de situação, buscam-se as condições objetivas e concretas em que dado fenômeno se manifesta e, no segundo momento, a análise enfoca a qualidade das forças políticas presentes nas condições objetivas e concretas identificadas. É neste segundo momento, em que se analisam as forças políticas a que Gramsci (1984) se refere, que se podem identificar três graus ou níveis de organização e consciência de ordem coletiva.

Dois desses graus pertencem ao momento econômico-corporativo. O primeiro é o mais elementar e pode ser apreendido pelo seguinte exemplo “(...) um comerciante sente que deve ser solidário com outro comerciante, um fabricante com outro fabricante. Assim, sente-se a unidade homogênea do grupo profissional e o dever de organizá-la (...)" (Gramsci, 1984, p. 49). Nesta perspectiva teórica, pode-se entender o movimento histórico do sindicalismo docente no país e identificar que esta característica, de perceberem-se como portadores de interesses individuais semelhantes, é o que tornou e torna possível a organização coletiva dos professores.

O segundo grau de desenvolvimento da organização coletiva "é aquele em que se adquire a consciência da solidariedade de interesses entre todos os membros do grupo social, mas no campo meramente econômico" (Gramsci, 1984, p. 49). Neste grau, conforme Gramsci, os grupos já se colocam diante da questão do Estado, porém, nos marcos das possibilidades da igualdade político-jurídica entre subordinados e dominantes; momentos de reivindicações de participação, ou seja, “(...) reivindica-se o direito de participar da legislação e da administração e, talvez, de modificá-las, reformá-las, mas nos quadros fundamentais já existentes" (Gramsci, 1984, p. 50).

Por fim, o momento ético-político, para Gramsci (1984, p. 50), é o momento em que um grupo social se coloca diante da questão da hegemonia e adquire a consciência de que seus interesses “(...) superam o círculo corporativo, de grupo meramente econômico, e podem e devem tornar-se os interesses de outros grupos subordinados". Neste sentido, considera-se que o grau de consciência ético-político se expressa tanto no debate como na luta que determinados grupos fazem em relação a questões que lhes dizem respeito.

Logo, alguns dos temas que aparecem no debate sobre saúde/adoecimento docente podem não ser plenamente considerados como pertinentes ao plano ético-político. Mas eles são considerados por suas possibilidades, ou pela potencialidade de mediarem processos de catarse, no sentido gramsciano, em 
que se passa de uma consciência atrelada ao momento econômico-corporativo para o ético-político.

Os resultados encontrados na pesquisa também foram analisados na perspectiva teórica de que o processo da saúde ou doença é determinado socialmente. Para tanto, cabem algumas considerações.

No âmbito da saúde dos trabalhadores é preciso explicitar o que se entende por doença, tal qual refere Laurell (1983), a fim de superar seu sentido médico-clínico (biológico e individual) e de incapacidade para o trabalho. Conceituar saúde implica articulá-la a um conceito social que, como produção humana e histórica, é formado por fenômenos inter-relacionados, conectados e articulados ontologicamente. Este entendimento permite compreender a saúde humana como um processo dinâmico. Daí a denominação processo saúde-doença, em que as dimensões biológica e social do ser humano estão em simultânea processualidade, no viver.

Para Breilh (1991), os agravos à saúde decorrem de processos de deterioração, tanto no trabalho como no consumo. Então, é significativo o postulado de que a saúde depende de como os indivíduos e grupos sociais se apropriam do que é produzido socialmente (não apenas insumos materiais para a sobrevivência, mas, também, bens socioculturais) (Breilh, 1991). A saúde, no seu sentido ampliado, como um processo determinado socialmente, concebe que o ser humano é mais que o biológico: é um ser social, que precisa de mais coisas do que de manter-se em pé, vivo. Mas, manter-se vivo é, ainda, uma prioridade ontológica (Lukács, 2013). Para reproduzir-se, e para que cada um, na sociedade, adquira o grau de humanidade que a humanidade atingiu (Albuquerque e Silva, 2014), ou seja, para serem incluídos no processo de um 'vir a ser' da generidade humana (Lukács, 2013), e fazer uso do que já existe para ampliar o tempo de vida, nas melhores condições físicas, psicológicas e ambientais possíveis, é preciso encaminhar os processos e as relações sociais para o provimento da emancipação humana, mediante a práxis política.

A determinação social, neste sentido, não pode ser entendida como sinônimo de determinismo econômico, tal qual o discutido por Fontes (2009) e Breilh (2006). Pode-se dizer que o determinismo econômico é uma condição da qual o capitalismo mantém a característica de ser movido e mover as relações sociais pelo valor de troca, na dimensão do mercado. Tudo, neste sistema pode ser convertido em valor de troca e, assim, ter um valor mercantil. A saúde é um dos bens sociais que vem, cada vez mais, sendo defendida como mais uma mercadoria.

A mercantilização de bens sociais, que fazem parte do ser social e do gênero humano, converte as reivindicações sociais em conquistas transitórias, que não se solidificam como direitos conquistados. Defende-se que a saúde, na agenda dos movimentos sociais e dos movimentos dos trabalhadores, precisa ser considerada no seu sentido ontológico e retomar o curso da conquista, da 
manutenção e das reivindicações ao direito humano e fundamental da saúde, que parecem em meio à mercantilização da vida.

O pressuposto que fundamenta este trabalho, portanto, é o de que defender a saúde como direito humano e social vai além da luta pela saúde suficiente (Ribeiro, 1999) para a reprodução da força de trabalho. É preciso tornar esta defesa uma questão de classe que se projete com base nos interesses da classe trabalhadora. E mais, acredita-se que é na luta pela saúde como direito humano e social que se obtém uma aproximação ao seu sentido ontológico (Ramos, 2005), ou seja, quando as necessidades do ser humano como sujeito são identificadas, a saúde não é vista como um objeto ou fator de produção.

Desse marco teórico foi possível organizar e sistematizar as unidades temáticas, extraídas das referências sobre saúde, presentes nos referidos documentos. Assim, foram classificadas, de acordo com sua aproximação com as reivindicações por saúde, a uma natureza econômico-corporativa ou éticopolítica, como está apresentado no Quadro 1.

\begin{tabular}{|c|c|c|}
\hline \multicolumn{3}{|c|}{ Natureza dos temas sobre saúde presentes nas resoluções congressuais da CNTE, no período de 1999 a 2014} \\
\hline Ano & Natureza econômico-corporativa & Natureza ético-política \\
\hline \multirow{10}{*}{1999} & Adoecimento no trabalho como & Saúde como direito social; \\
\hline & problema da categoria e não individual; & \\
\hline & & Saúde garantida por meio de política pública - \\
\hline & Condições de trabalho, na sua relação com & dever do Estado de garantir saúde; \\
\hline & a saúde, deve ter um tratamento sindical; & \\
\hline & & Saúde e baixa qualidade dos serviços públicos de \\
\hline & Estado (como empregador) é responsável & saúde; \\
\hline & pelas condições de trabalho precárias; & Saúde e mercado (mercantilização da saúde); \\
\hline & Tratamento dos trabalhadores adoecidos; & Saúde na abordagem curativista; \\
\hline & Necessidade de reivindicação de melhores & Saúde na perspectiva da assistência. \\
\hline \multirow{3}{*}{2002} & & Saúde e qualidade de vida dos trabalhadores; \\
\hline & (Não foram identificados temas & Serviços públicos de qualidade; \\
\hline & neste documento) & Saúde, gênero e etnia. \\
\hline
\end{tabular}


Continuação - Quadro 1

Natureza dos temas sobre saúde presentes nas resoluções congressuais da CNTE, no período de 1999 a 2014

\section{Ano Natureza econômico-corporativa}

Condições de trabalho e saúde dos

trabalhadores da educação;

Formação do Coletivo de Saúde;

Necessidade de uma nova abordagem dos

2005 trabalhadores diante da doença profissional

(reivindicar diagnóstico adequado e

notificação dos casos, e promover denúncias);

Comissão Interna de Prevenção de Acidentes

(Cipa) nas escolas.

Articular a CNTE à Política Nacional de

Saúde do Trabalhador, da Central Única dos

2008 Trabalhadores (CUT);

Defender a Segurança e Promoção da Saúde

do Trabalhador nos locais de trabalho;

Cipas nas escolas.

Valorização profissional;

Condições de trabalho e saúde;

Gestão da educação e saúde;

Combater estresse no trabalho e Lesões

por Esforço Repetitivo (LER);

Prevenção a Doenças Sexualmente

Transmissíveis (DSTs) e à Síndrome da

Imunodeficiência Adquirida (Aids).

Saúde, previdência e aposentadoria;

Saúde dos educadores e condições

de trabalho;

Políticas de prevenção e tratamento às

2014 doenças características da profissão;

Cipas nas escolas;

Readaptação e/ou reenquadramento

funcional dos(as) educadores(as) em

tratamento de saúde.

\section{Natureza ético-política}

Saúde como um dos princípios para a valorização do trabalho;

Saúde dos trabalhadores e a necessária relação entre saúde e condições de trabalho.

Ampliação de direitos:

Saúde, gênero e etnia.

Saúde e qualidade dos serviços públicos de saúde; Luta por direitos;

Luta sindical por direitos intrínsecos ao bem-estar da classe trabalhadora, pelos direitos afetos às relações de trabalho, e pelos direitos individuais; Políticas de saúde;

Financiamento da saúde;

Reforma urbana;

Saúde, gênero e etnia.

Financiamento da saúde;

Fortalecimento e Qualificação do Sistema

Único de Saúde (SUS);

Saúde, gênero e etnia

Fonte: Elaboração própria.

Nota: CNTE - Confederação Nacional dos Trabalhadores em Educação. 
Conforme o Quadro 1, os temas pertinentes a uma natureza econômicocorporativa estão articulados a dois conjuntos de questões. No primeiro, estão aqueles que tratam da questão do adoecimento no trabalho como um problema da categoria, e não como um problema individual. Daí as condições de trabalho aparecerem como elemento importante a ser observado na agenda política, por estarem relacionadas à questão da saúde coletiva. Pode-se dizer que é pela mediação do estudo e diagnóstico das situações em que o trabalho dos professores é realizado que é possível avançar no sentido do estabelecimento dos nexos entre essas e outras determinadas formas de adoecimento. Neste aspecto, um dos temas manifestos é reivindicar melhores condições de trabalho nas escolas e a responsabilização do Estado, como empregador, por estas circunstâncias precárias e pelo tratamento dos trabalhadores adoecidos. Note-se também que, em 2014, além dos temas que já apareciam nos referidos documentos, os temas saúde, previdência e aposentadoria foram incluídos como políticas permanentes da entidade, e enfatizou-se a necessidade de elaborar novas políticas que abrangessem prevenção, tratamento, readaptação, reenquadramento e tratamento de saúde para os trabalhadores da educação.

Ao longo do debate sobre a saúde/adoecimento dos trabalhadores da educação, coletivizar o problema foi identificado como um aspecto essencial. O processo de assumir a saúde como parte das lutas da CNTE, na qual se identificou, em um primeiro momento, que os problemas vividos por professores no âmbito individual era um problema vivenciado pela categoria, propiciou criar espaços institucionais para o debate das questões.

Pode-se dizer que esta fase de apreender a especificidade do problema saúde/doença da categoria é uma passagem importante no momento econômicocorporativo da entidade sindical, que engendrou a necessidade de produzir pautas sindicais. Estas pautas, conforme Gouvêa (2016), são as seguintes: participar e realizar atividades de pesquisa; criar espaços institucionais para o tratamento da questão, tais como Coletivos de Saúde e Secretaria de Saúde dos Trabalhadores; formação sindical; publicações em forma de dossiês; e pautar o tema nos debates sobre valorização dos profissionais da educação, nos fóruns educacionais em âmbito nacional.

No segundo conjunto de temas, estão ainda aqueles que preconizam a adoção de algumas medidas ou ações mais específicas, como se observa no Quadro 1, e que, para tanto, em 2005, foi a formação do Coletivo de Saúde da CNTE e, em 2008, a articulação da CNTE à Política Nacional de Saúde do Trabalhador, da Central Única dos Trabalhadores (CUT). No que concerne a medidas preventivas, predominou a proposta de formar uma Comissão Interna de Prevenção de Acidentes (Cipa) nas escolas, incluída como pauta desde o ano de 2005, e o combate e a prevenção de agravos à saúde específicos, como Lesão por Esforço Repetitivo (LER), Doenças Sexualmente Transmissíveis (DSTs) e Síndrome da Imunodeficiência Adquirida (Aids). Em 2014, incluiu-se a necessidade de se fazer uma campanha nacional de denúncia sobre as condições 
de trabalho e saúde dos trabalhadores da educação. Estas diretrizes pontuais da CNTE, a fim de engendrar ações práticas no que se referem a processos de melhorias nas circunstâncias de trabalho nas escolas, são importantes e merecem ser analisadas de forma mais detalhada. Daí sugere-se, para pesquisadores, a realização de novos estudos que contemplem não somente o que a entidade sindical propõe para a escola, mas também que experiências estão sendo desenvolvidas com sucesso no país.

No que concerne à análise dos temas considerados como aproximados a uma natureza ético-política, relacionados no Quadro 1, optou-se por classificá-los em três conjuntos de temas, a saber: defesa de princípios e políticas; denúncia dos problemas afetos à questão; e proposições de ação sindical.

Nesse sentido, os temas de natureza ético-política presentes nas resoluções da CNTE dizem respeito, primeiramente, à defesa da saúde como direito social e à garantia de condições de saúde para os trabalhadores, por meio de políticas públicas de responsabilidade do Estado.

Como a saúde é um dos pressupostos para a qualidade de vida dos trabalhadores, os serviços públicos oferecidos pelo Estado devem ter qualidade e, portanto, precisam de financiamento e gestão pública adequados. Desta forma, em relação às políticas públicas de saúde, a entidade sindical refere haver necessidade de se defender o fortalecimento e lutar pela qualificação do SUS (CNTE, 1999; 2002; 2005). Este aspecto é reforçado quando se entende que a valorização do trabalho, e do trabalhador, passam, necessariamente, pela questão da saúde dos trabalhadores.

Evidencia-se ainda que, ao orientar sua defesa ao direito à saúde e fazer proposições para garanti-lo, a entidade sindical aproxima seu posicionamento do conceito de saúde ampliado, tal qual foi inscrito na Constituição Federal de 1988: “A saúde é um direito de todos e dever do Estado, garantido mediante políticas sociais e econômicas que visem à redução do risco de doença e de outros agravos e ao acesso universal e igualitário às ações e serviços para sua promoção, proteção e recuperação" (Brasil, 1988).

Esta elaboração, presente na Constituição Federal, é considerada como um conceito ampliado de saúde, por ir além de elementos conceituais pertinentes à prevenção ou ao tratamento de enfermidades, ou ao adoecimento. Neste último aspecto, contrapõe-se ao que se denomina de conceito restrito de saúde, isto é, como ausência de doença ou, então, como uma questão restrita ao biológico. Ao postular que o Estado tem o dever de garantir o direito à saúde, a Constituição explicita que deve fazê-lo por meio de ações intersetoriais e articuladas, que abranjam as políticas sociais e econômicas e proporcionem garantia de acesso da população à rede assistencial. A regulamentação dos serviços de saúde, para atender ao preceito constitucional, foi dada pela lei $\mathrm{n}$. 8.080/1990, que dispõe sobre o SUS e inclui um desenvolvimento conceitual entendido como um complemento do que está disposto na Constituição Federal, 
referente ao dever do Estado de prover condições para o pleno exercício da saúde como direito. Na citada legislação, ser saudável, como processo vital de indivíduos e coletividades, resulta de determinantes e condicionantes, entre eles, conforme seu artigo 30: “(...) a alimentação, a moradia, o saneamento básico, o meio ambiente, o trabalho, a renda, a educação, o transporte, o lazer e o acesso aos bens e serviços essenciais (...)" (Brasil, 1990). Estes determinantes sociais, como elencados, ao se constituírem como problemas sociais, são, eles mesmos, objetos de políticas sociais específicas, todas atreladas às políticas econômicas adotadas em cada momento conjuntural.

Como políticas sociais, tais questões também fazem parte de direitos constitucionais e, daí, pode-se inferir que a CNTE também contempla, em suas proposições, a defesa de tais direitos. Isto é observado quando a entidade sindical explicita que é necessário lutar pela ampliação de direitos, por meio da eleição de pautas da instituição que contemplem reivindicações de direitos, não apenas aqueles pertinentes às relações de trabalho, mas sobretudo aqueles referentes ao bem-estar da classe trabalhadora (CNTE, 2002; 2005; 2008; 2011).

Outra conduta da CNTE, em relação a propostas sobre a saúde presentes nos documentos pesquisados, refere-se à necessidade de estabelecer nexos entre saúde e condições de trabalho, e enfatizar, neste debate, uma perspectiva de gênero e etnia. O primeiro destes temas, remete a incluir grandes temas sobre o trabalho na conjuntura do capitalismo brasileiro, em que há um processo de perda de direitos trabalhistas e previdenciários conquistados duramente pela classe trabalhadora.

Quanto às perspectivas de gênero e etnia, consideram-se, neste trabalho, como temas relacionados ao plano ético-político, sempre que a o debate se faça com os devidos encadeamentos entre gênero, etnia e classe social. Conduzir as análises e as proposições a fim de superar as tradicionais formas de se discriminar e desvalorizar o trabalho realizado pelo sexo feminino, potencializadas pelo sistema capitalista, e que, articuladas às questões étnicas, constituem um fenômeno de precarização ainda mais intenso do trabalho feminino.

A esse respeito, Breilh (2006) refere que, após a Segunda Guerra Mundial, as mulheres proletárias e as de classe média tiveram que lutar para que suas reivindicações não se dissolvessem nas reclamações gerais de classe. Conseguiram promover suas próprias reivindicações, consubstanciadas, inicialmente, no movimento feminista, e descortinaram uma nova e fundamental linha de emancipação, ou seja, a emancipação feminina. No mesmo sentido, Breilh (2006) refere que os grupos étnicos também iniciaram sua luta pelo mundo no sentido de estabelecerem projetos de emancipação étnica, diferenciados em vários países. Mesmo diante de algumas especificidades das necessidades do gênero feminino e de algumas etnias, as reivindicações em relação à saúde precisam articular-se na direção da garantia dos direitos e definindo-a, também, como direito à saúde no trabalho. 
Quanto às denúncias referentes à violação do direito à saúde, feitas pela CNTE, nota-se que 1999 consolidou-se como o momento em que mais se desenvolveu este tema nas análises conjunturais da instituição (CNTE, 1999). Isto pode ter relações com a publicização da pesquisa sobre as condições de trabalho e saúde mental dos trabalhadores da educação (Codo, 2002) e, também, pelo contexto histórico vivido naquele momento, caracterizado por ajustes estruturais e condução de políticas sociais nos moldes neoliberais. Os temas mais frequentes foram: baixa qualidade dos serviços públicos, entre eles, os serviços de saúde oferecidos para a população trabalhadora; mercantilização na área da saúde; e predomínio de uma abordagem curativista, em detrimento do aspecto preventivo. Todos temas importantes a serem denunciados e que apareceram de forma enfática, também, na resolução congressual de 2011.

De uma forma geral, diante dos resultados da pesquisa, conforme o exposto, identificou-se o engajamento da CNTE nas questões da saúde dos trabalhadores da educação no período considerado, com temas tanto pertinentes a uma natureza econômico-corporativa como próximos a uma natureza ético-política.

Ao buscar identificar que concepções de saúde ou doença permeiam os discursos da entidade sindical em foco, um dos limites da presente pesquisa é o de não ter se voltado para análise do contexto histórico e motivos que condicionaram a inclusão de determinados temas relacionados à saúde nos congressos nacionais da CNTE e, por conseguinte, registrados nas suas resoluções congressuais.

Portanto, sugere-se a pesquisadores interessados na temática, o estudo sobre como as teses congressuais são elaboradas, inscritas e incluídas na pauta congressual da instituição. Ou seja, podem-se evidenciar, entre outros elementos, grupos que se esforçam em incluir a questão da saúde dos trabalhadores da educação nestes fóruns institucionais, e que forças políticas orientam-nos.

Pode-se afirmar que a saúde como direito humano, direito fundamental social e direito à vida, está presente na agenda da CNTE, ao menos nos documentos estudados. Considera-se que, para desenvolver estes pressupostos na abordagem da saúde dos trabalhadores da educação, propondo ações práticas mais abrangentes no âmbito escolar, é preciso avançar na discussão destes temas junto aos professores e demais trabalhadores da educação.

Por fim, compreende-se que a discussão da saúde no seu sentido econômico - como fator de reprodução da força de trabalho - e no sentido de direito humano, social e ontológico - permite a apreensão das características que precisam estar presentes nas reivindicações de saúde como direito social na perspectiva da classe trabalhadora. Isto deve se contrapor ao sentido estritamente econômico, tal qual se exprime nos direcionamentos das políticas públicas. Daí deve-se compreender que é a mediação da defesa da saúde como direito humano e social que pode desenvolver ações sindicais que se aproximem de uma natureza ético-política, ou seja, na qual se defenda a saúde 
como direito de todos os trabalhadores e trabalhadoras, não só nos locais de trabalho, mas na amplitude da vida em sociedade.

\section{Conclusões}

Por meio dos conceitos de momento econômico-corporativo e momento ético-político, foi possível classificar as reivindicações por saúde presentes na instituição. De acordo com o que foi exposto, entende-se que a saúde dos trabalhadores da educação tem sido incorporada na pauta sindical dos professores, na CNTE, por meio de uma compreensão de saúde que transita entre uma concepção de saúde mais restrita e corporativa e outra mais ampliada. Observou-se que há um movimento na entidade sindical em prol de uma agenda política em defesa da saúde como direito social e, assim, considera-se que há um comprometimento da instituição em ampliar o debate, para além do plano corporativo.

Pode-se dizer que a CNTE, nos limites de uma entidade sindical, vem, aos poucos, engendrando sua luta pela saúde dos trabalhadores da educação. Contudo, embora os documentos analisados possibilitassem a interpretação de que, na instituição estudada, há a defesa de uma concepção de saúde ampliada, ainda há uma necessidade de se estudar, por meio de pesquisas nacionais, o que professores (sindicalizados e não sindicalizados) reivindicam em relação à saúde, a fim de se identificar que concepções estão presentes nas falas destes profissionais. Compreende-se que, na luta por direitos, e neles mesmos, o direito humano e fundamental à saúde tem ainda muito a ser construído e defendido pela classe trabalhadora como um todo. Não há como separar a luta reivindicatória por direitos à saúde e à segurança no trabalho da luta pelo direito à saúde e da luta pelo direito à vida. Neste artigo, considera-se que a saúde não está limitada apenas às condições de trabalho, mas sobretudo é determinada pelo direito à saúde no seu sentido ontológico. Assim, a defesa da saúde como bem público depende da participação, organização e luta dos trabalhadores de maneira coletiva, além do âmbito corporativista.

Esta agenda política pode ser compreendida como um importante e fecundo recurso para se ampliar o debate da saúde dos trabalhadores da educação no âmbito ético-político e reforçar o argumento de que é preciso incluir o aspecto ontológico da saúde ao defendê-la como direito social. Tema que, na nova conjuntura brasileira, se reveste de desafios importantes para todos os trabalhadores. 


\title{
Agradecimentos
}

\begin{abstract}
A Marise Nogueira Ramos, orientadora da tese que deu origem a este artigo e professora no Programa de Pós-Graduação em Políticas Públicas e Formação Humana da Universidade do Estado do Rio de Janeiro.
\end{abstract}

Resumen El objetivo de esto estudio es identificar y analizar conceptos de salud presentes en las reivindicaciones de los profesores en la Confederación Nacional de los Trabajadores en Educación. Es el resultado de pesquisa documental realizada en las resoluciones congresuales de la entidad sindical entre los años de 1999 y 2014. Por medio del análisis de contenido, las referencias a la salud presentes en los documentos fueran clasificadas en reivindicaciones próximas a una naturaleza económico-corporativa o ético-política. Los resultados de la pesquisa indican que, además de una concepción restricta de la salud marcada por reivindicaciones corporativas, la documentación investigada presenta una concepción ampliada. La reivindicación de la salud, desde la perspectiva de un derecho social garantizado mediante políticas públicas, pude ser un camino fértil para la defensa de la salud en el sentido ontológico, y no como un factor económico, comprendido como mercancía y bastante para la reproducción de la fuerza de trabajo.

Palabras clave docentes; salud del trabajador; derecho a la salud; sindicatos.

\section{Notas}

${ }^{1}$ Universidade Estadual do Oeste do Paraná, Centro de Ciências Biológicas e da Saúde, Cascavel, Paraná, Brasil.

<ledanabuco@yahoo.com.br>

Correspondência: Universidade Estadual do Oeste do Paraná, Centro de Ciências Biológicas e da Saúde, Rua Universitária, Jardim Universitário, CEP 85814-110, Cascavel, Paraná, Brasil. 


\section{Referências}

ALBUQUERQUE, Guilherme S. C.; SILVA, Marcelo J. S. E. Sobre a saúde, os determinantes da saúde e a determinação social da saúde. Saúde em Debate, Rio de Janeiro, v. 38, n. 103, p. 953965, out.-dez. 2014. Disponível em: <http:// cebes.org.br/site/wp-content/uploads/2015/02/ RSD103_Web.pdf.pdf>. Acesso em: jan. 2015.

APEOESP. Sindicato dos Professores do Ensino Oficial do Estado de São Paulo. A saúde dos professores. São Paulo: Cepes/APEOESP. 2012. Disponível em: <http://www.apeoesp.org.br/d/ sistema/publicacoes/390/arquivo/1-saude-dosprofessores.pdf $>$. Acesso em: 15 jun. 2014.

BRASIL. Constituição (1988). Constituição da República Federativa do Brasil. Brasília, DF: Senado, 1988.

BRASIL. Casa Civil. Lei n. 8.080, de 19 de setembro de 1990. Dispõe sobre as condições para a promoção, proteção e recuperação da saúde, a organização e o funcionamento dos serviços correspondentes e dá outras providências. 1990. Disponível em: $<$ http://www.planalto.gov.br/ccivil_03/leis/L8080. htm>. Acesso em: 15 jan. 2013.

BREILH, Jaime. Epidemiologia: economia, política e saúde. São Paulo: Unesp/Hucitec, 1991.

BREILH, Jaime. Epidemiologia crítica: ciência emancipadora e interculturalidade. Rio de Janeiro: Editora Fiocruz, 2006.

CALDAS, Andrea R. Trabalho docente e saúde: inquietações trazidas pela pesquisa nacional com professores(as) da educação básica. In: OLIVEIRA, Dalila A.; VIEIRA, Lívia F. (orgs.). Trabalho na educação básica: a condição docente em sete estados brasileiros. Belo Horizonte: Fino Traço, 2012. p. 429-445.

CNTE. Confederação Nacional dos Trabalhadores em Educação. CONGRESSO NACIONAL DOS TRABALHADORES EM EDUCAÇÃO, 27. Terra, trabalho, salário e educação: desafios para o século XXI. Goiânia, janeiro, 1999. Caderno de Resoluções. Brasília, DF: CNTE, 1999.
CNTE. Confederação Nacional dos Trabalhadores em Educação. CONGRESSO NACIONAL DOS TRABALHADORES EM EDUCAÇÃO, 28.: Construir outro projeto para o Brasil. Blumenau, janeiro, 2002. Caderno de Resoluções. Brasília, DF: CNTE, 2002.

CNTE. Confederação Nacional dos Trabalhadores em Educação. Retrato da escola 3: relatório de pesquisa sobre a situação dos trabalhadores(as) da Educação Básica. Brasília: CNTE, 2003. Disponível em: <http://www.cnte.org.br/images/ stories/2012/pesquisa_retrato_da_escola_3. pdf>. Acesso em: 10 mar. 2014.

CNTE. Confederação Nacional dos Trabalhadores em Educação. CONGRESSO NACIONAL DOS TRABALHADORES EM EDUCAÇÃO, 29. Educação pública só é prioridade com mais financiamento. Já passou da hora. Brasília, janeiro, 2005. Caderno de Resoluções. Brasília, DF: CNTE, 2005.

CNTE. Confederação Nacional dos Trabalhadores em Educação. CONGRESSO NACIONAL DA CNTE, 30. Brasília, janeiro, 2008. Caderno de Resoluções. Brasília: CNTE, 2008.

CNTE. Confederação Nacional dos Trabalhadores em Educação. CONGRESSO NACIONAL DOS TRABALHADORES EM EDUCAÇÃO, 31. O PNE na visão dos(as) trabalhadores(as) em educação. Brasília, janeiro, 2011. Caderno de Resoluções. Brasília, DF: CNTE, 2011.

CNTE. Confederação Nacional dos Trabalhadores em Educação. CONGRESSO NACIONAL DOS TRABALHADORES EM EDUCAÇÃO, 32. Educação, desenvolvimento e inclusão social. Brasília, janeiro, 2014. Caderno de Resoluções. Brasília, DF: CNTE, 2014.

CNTE. Confederação Nacional dos Trabalhadores em Educação. A CNTE. 2016. Disponível em: <http://www.cnte.org.br/index. $\mathrm{php} /$ institucional/a-cnte.html $>$. Acesso em: 2 jun. 2016.

CODO, Wanderley (coord.). Educação: carinho e trabalho. 3. ed. Petrópolis: Vozes; Brasília: 
CNTE; UnB - Laboratório de Psicologia do Trabalho, 2002.

DIAS, Elizabeth C.; HOEFEL, Maria da G. O desafio de implementar as ações de saúde do trabalhador no SUS: a estratégia da RENAST. Ciência \& Saúde Coletiva, Rio de Janeiro, v. 4, n. 10, p. 817-828, 2005.

FONTES, Virgínia. Determinação, história e materialidade. Trabalho Educação e Saúde, Rio de Janeiro, v. 7, n. 2, p. 209-229, jul.-out.2009.

GASPARINI, Sandra M. et al. O professor, as condições de trabalho e os efeitos sobre sua saúde. Educação e Pesquisa, São Paulo, v. 31, n. 2, p. 189-199, maio-ago. 2005.

GOMES, Romeu. A análise de dados em pesquisa qualitativa. In: MINAYO, Maria Cecília S. (org.). Pesquisa social: teoria, método e criatividade. 18. ed. Petrópolis: Vozes, 2001. p. $67-80$.

GOUVÊA, Leda A. V. N. As condições de trabalho e o adoecimento de professores na agenda de uma entidade sindical. Revista Saúde em Debate, Rio de Janeiro, v. 40, n. 111, p. 206-219. 2016. Disponível em: <http://www.saudeemdebate.org.br/artigos/ artigo_int.php?id_artigo $=4375>$. Acesso em: 30 mar. 2016.

GRAMSCI, Antonio. Maquiavel, a politica e o Estado moderno. Rio de Janeiro: Civilização Brasileira, 1984.

GRAMSCI, Antonio. Concepção dialética da história. Rio de Janeiro: Civilização Brasileira, 1986.

LACAZ, Francisco A. C. Saúde dos trabalhadores: cenário e desafios. Cadernos de Saúde Pública, Rio de Janeiro, v. 13, supl. 2, p. S07-S19, 1997.

LACAZ, Francisco A. C.; SANTOS, Ana P. L. Saúde do Trabalhador, hoje: revisitando atores sociais. Revista Médica de Minas Gerais, Belo Horizonte, v. 20, supl. 2, p. 5-11, 2010.
LAURELL, Asa C. A saúde-doença como processo social. In: NUNES, Everardo D. Medicina Social: aspectos históricos e teóricos. Global: São Paulo, 1983. p. 132-158.

LEITE, Marcia de P.; SOUZA, Aparecida N. Condições de trabalho e suas repercussões na saúde dos professores da educação básica no Brasil. Educação e Sociedade, Campinas, v. 32, n. 117, p. 1.105-1.121, dez. 2011.

LUKÁCS, György. Para uma ontologia do ser social. 2 v. São Paulo: Boitempo, 2013. v. 2.

OLIVEIRA, Dalila A. Apresentação. In: OLIVEIRA, Dalila A.; VIEIRA, Lívia F. (orgs.). Trabalho na educação básica: a condição docente em sete estados brasileiros. Belo Horizonte: Fino Traço, 2012. p. 9-17.

RAMOS, Marise N. Integralidade na atenção e na formação dos sujeitos: desafio para a educação profissional em saúde. In: PINHEIRO, Roseni; MATTOS, Ruben A. (orgs.). Construção social da demanda: direito à saúde, trabalho em equipe, participação e espaços públicos. 2. ed. Rio de Janeiro: Cepesc/UERJ; Abrasco, 2005.

RIBEIRO, Herval P. A violência oculta do trabalho: as lesões por esforços repetitivos. Rio de Janeiro: Editora Fiocruz, 1999.

ROBALINO, Magaly. A saúde e o trabalho docente: um desafio para as políticas públicas da educação. In: OLIVEIRA, Dalila A.; VIEIRA, Lívia F. (orgs.). Trabalho na educação básica: a condição docente em sete estados brasileiros. Belo Horizonte: Fino Traço, 2012. p. 371-397.

VIEIRA, Juçara D. Confederação Nacional dos Trabalhadores em Educação - CNTE. In: OLIVEIRA, Dalila A. et al. Dicionário: trabalho, profissão e condição docente. Belo Horizonte: UFMG/Faculdade de Educação, 2010. 1 CD-ROM.

Recebido em 02/04/2017.

Aprovado em 05/06/2017. 